\title{
Systematic review and meta-analysis of therapeutic effects of pelvic restoration combined with anti-stress urinary incontinence surgery on pelvic floor dysfunction
}

\author{
Jing Liu", Lijun Li", Siyuan Bv, Peng He, Mingxing Qiu, Zhiwei Ma \\ Department of urology, Sichuan Provincial People's Hospital, University of Electronic Science and Technology of China, Chengdu, China \\ Contributions: (I) Conception and design: J Liu, L Li, M Qiu, Z Ma; (II) Administrative support: S Bv; (III) Provision of study materials or patients: \\ J Liu, L Li, P He, Z Ma; (IV) Collection and assembly of data: All authors; (V) Data analysis and interpretation: J Liu, L Li, S Bv, M Qiu; (VI) \\ Manuscript writing: All authors; (VII) Final approval of manuscript: All authors. \\ "These authors contributed equally to this work. \\ Correspondence to: Mingxing Qiu; Zhiwei Ma. 32 West second Section, First Ring Road, Qingyang District, Chengdu, Sichuan, China. \\ Email: qmx3687@163.com; mzw3690@163.com.
}

Background: In recent years, pelvic restoration surgery is widely used in the diagnosis and treatment
of stress urinary incontinence (SUI) as people pay more attention to postpartum pelvic floor dysfunction
(PFD). The therapeutic effect of pelvic restoration combined with anti-SUI surgery remains undetermined.
The evaluation indicators of the therapeutic effects include the incidence of postoperative obstruction, the
incidence of postoperative defecation difficulties, and the quality of life score.

Methods: PubMed, Cochrane Library, and EMBASE were searched from the establishment of the database to April 2021 for randomized control trials (RCTs) of pelvic restoration and anti-SUI surgery, and the RevMan5.3 software provided by the Cochrane Collaboration was used for meta-analysis.

Results: A total of 6 documents (a total of 1,944 patients) were included, including 1,021 patients in the experimental group and 923 patients in the control group. The incidence of obstruction after pelvic restoration combined with anti-SUI surgery was statistically significant (OR $=1.35,95 \%$ CI, 0.95-1.92, $\mathrm{P}=0.10)$; there was a statistically significant difference in the incidence of postoperative dyspareunia (OR $=1.58,95 \%$ CI, 0.91-2.74, P=0.10).

Discussion: A total of 8 documents included in this meta-analysis confirmed that pelvic restoration combined with anti-SUI surgery for PFD can improve the prognosis and quality of life of patients.

Keywords: Pelvic restoration; surgery for stress urinary incontinence; pelvic floor dysfunction (PFD); metaanalysis

Submitted Sep 07, 2021. Accepted for publication Nov 03, 2021.

doi: 10.21037/apm-21-2737

View this article at: https://dx.doi.org/10.21037/apm-21-2737

\section{Introduction}

Pelvic floor dysfunction (PFD) mainly arises from defects or injuries of the pelvic floor supporting tissue and urinary incontinence (UI) is a common disease of PFD. The incidence of UI in women is much higher than in men due to women's special pelvic floor structure and hormone levels (1). Its incidence varies from $5 \%$ to $69 \%$ resulting from differences in various countries, observation methods, races, and socioeconomic conditions. Large-scale epidemiology shows that the incidence of UI in adult women is $30.9 \%$ in China (2). UI harms women's physiological, social, and sexual functions and has become a global health problem. The World Health Organization lists it as one of the five most common chronic diseases that threaten women's health (3). Many factors cause UI in women. Epidemiological data show that pregnancy and childbirth are independent risk factors 
for UI $(4,5)$. Statistics show that the incidence of UI during pregnancy is $35-67 \%$ and the incidence of postpartum UI is $5-21 \%$ (6). A multi-center prospective study in 2012 found that the incidence of UI in the third trimester, 6 weeks after pregnancy, and 6 months after pregnancy of primipara was $26.7 \%, 9.5 \%$, and $6.8 \%$, respectively, mainly stress urinary incontinence (SUI) $(7,8)$. It is easy to develop UI during pregnancy and childbirth due to the increase in abdominal pressure and the decrease in the collagen of the pelvic floor support structure which reduces the pelvic floor muscle strength and relaxes the pelvic floor support tissue (9).

The prevention and treatment methods of UI mainly include surgical treatment and non-surgical treatment. Among them, non-surgical treatment can be divided into primary disease treatment, behavioral therapy, physical therapy and drug therapy. For patients with poor nonsurgical treatment, intolerance or poor compliance, surgical treatment can be selected. In addition, patients with moderate to severe pelvic organ prolapse can directly choose surgical treatment, such as mid-urethral sling surgery. As people's understanding of SUI deepens, it has been found that the connective tissue of the paravaginal fascia and nearby ligaments plays a role in the restoration of the pelvic floor (10). Pelvic floor repair can significantly improve the symptoms of organ prolapse, thereby improving the quality of life of patients. As a new type of treatment, the patch is controversial in the treatment of PFD because its complications are becoming more and more prominent.

At present, there are relatively few studies on systematic evaluation of pelvic floor repair combined with antiSUI surgery for the treatment of pelvic floor dysfunction diseases, and the choice of outcome indicators also has certain limitations. This system can use mate analysis to evaluate the efficacy of pelvic floor repair combined with anti-SUI surgery in the treatment of PFD. A total of 8 articles were included in this study to review the pathological results at home and abroad, hoping to provide a scientific basis and theoretical reference for the treatment of PFD. We present the following article in accordance with the PRISMA reporting checklist (available at https:// dx.doi.org/10.21037/apm-21-2737).

\section{Methods}

\section{Literature retrieve}

PubMed, Cochrane Library, and EMBASE were searched for relevant RCTs with "pelvic floor repair", "pelvic floor dysfunction", "stress urinary incontinence", and "pelvic floor muscle training" as search terms. The search time was set from January 1, 2001 to April 2021. Then, the studies were identified according to the inclusion and exclusion criteria.

\section{Literature inclusion and exclusion criteria}

Inclusion criteria: (I) research type: RCTs regardless of whether allocation concealment or the blind method was used; (II) research subjects: women over 18 years of age who were diagnosed with SUI after childbirth and underwent pelvic restoration combined with anti-SUI surgery; (III) intervention measures: the experimental group used pelvic restoration combined with anti-SUI surgery for treatment, including tension-free middle urethral sling, Burch vaginal wall sling, bladder neck sling, artificial urethral sphincter, and Vaginal anterior wall repair surgery; the control group adopted anti-SUI surgery alone; and (IV) measurement indicators: main outcome indicators: postoperative obstruction rate, postoperative defecation dysfunction rate, postoperative bleeding or hematoma rate, and the incidence of postoperative dyspareunia; secondary outcome indicators: patient satisfaction score and quality of life index.

Exclusion criteria: (I) those with unclear data; (II) those published in Chinese; (III) not relevant to the study; (IV) non-RCTs; and (IV) those with unreliable results.

\section{Data extraction}

The data extraction was carried out independently by two researchers and any inconsistencies were solved by discussions or inviting a third researcher for arbitration. The data to be extracted for this study include basic information of the literature (document title, first author, publication year, author information, document source), basic characteristics of subjects (gender, age, research sample size, baseline comparability), literature research methods, research plan design, intervention measures for experimental group and control group, and outcome evaluation indicators.

\section{Quality evaluation}

The quality evaluation was carried out as per the bias risk assessment recommended by the Cochrane system review manual (version 5.3). The evaluation content includes the following 7 items. (I) Which random method to use; 
(II) whether to perform allocation concealment; (III) the implementation of blinding between patients and investigators; (IV) the effect of blinding; (V) whether the results were complete; (VI) whether the survey results were credible; and (VII) other biases. For each RCT, "satisfied" means small bias and "unsatisfied" means high bias. Each item scores 1 point and a total score between $1-3$ is considered low quality, and a total score between 4-7 is considered high quality.

\section{Data analysis}

The forest map clearly shows the results of each study. If there is no overlap between the confidence intervals of the results of each study, it indicates that there is statistical inhomogeneity between the studies. Sensitivity analysis: the sensitivity analysis investigates whether a single study affects the overall results of the combination. Generally speaking, it will have an impact on comprehensive research in the following two situations. First, when a study is deleted, the result will be significantly different. If there is little difference in the overall results when a study is deleted, it indicates the sensitivity of the combined results and the results obtained are unstable. On the contrary, the results show sensitivity and stability, and the conclusion is correct.

\section{Statistical analysis}

The RevMan5.3 software provided by the Cochrane Collaboration was used for Meta-analysis. The odds ratio (OR) was used as the effect size and $95 \%$ confidence interval (CI) expressed the result. The included studies were tested for heterogeneity first, with $\alpha=0.1$ as the test level. If there was no heterogeneity between the studies $(\mathrm{P}>0.1$, $\left.\mathrm{I}^{2}<50 \%\right)$, the fixed-effects model (FEM) was selected for meta-analysis; if there was heterogeneity between studies $\left(\mathrm{I}^{2}>50 \%\right)$, the random-effects model (REM) was selected for mate-analysis. $\mathrm{P}<0.05$ indicated that the difference was statistically significant. When a single risk factor analysis was included in more than 10 articles, a funnel chart was used to analyze the publication bias of each risk factor.

\section{Results}

\section{Literature retrieve results}

Of 783 literatures initially identified, 342 were retrieved from the database, 441 were retrieved from the registers. After reading the title, first remove 343 literatures that did not meet the requirements. After a cursory glance at the abstract of the article, 348 literatures that clearly did not meet the requirements were eliminated. After carefully reading the abstract of the literatures, 75 literatures were eliminated. After downloading the remaining literatures, 5 literatures with "unclear grouping" and 6 literatures with "outcome index data is not uniform" were removed. Finally, a total of 6 literatures meeting the requirements were included in the Mata analysis (11-16). The retrieval process was shown in Figure 1, and the basic information of the included literature was shown in Table 1.

\section{The literature bias risk assessment results}

The Cochrane Handbook version 5.3 systematic review writing manual was used to evaluate the bias risk of the 10 documents included in this study and the bias risk chart was output, as shown in Figure 2 and Figure 3, and the bias risk was expressed by the RevMan 5.3 software.

\section{Postoperative obstruction}

Five documents included in the study reported the probability of obstruction of patients after pelvic restoration combined with anti-SUI surgery. It was found that 81 out of 1,021 patients in the experimental group had obstruction, while 58 out of 923 patients in the conventional group had an obstruction. After the heterogeneity test, the results showed that $\mathrm{I}^{2}=0 \%, \mathrm{P}=0.83$, indicating there was obvious heterogeneity in the literature, and then the FEM was used for analysis. The meta-analysis results showed that $\mathrm{OR}=1.35,95 \% \mathrm{CI}: 0.95-1.92, \mathrm{Z}=1.66$, and $\mathrm{P}=0.10$. Therefore, there was a significant difference in the probability of obstruction after anti-SUI surgery between the two groups $(\mathrm{P}<0.05)$, as shown in Figure 4.

As shown in Figure 5, the funnel chart was symmetrical and most of the data corresponded to points within the $95 \%$ $\mathrm{CI}$, indicating that the publication bias was effective so that the results of the incidence of obstruction after anti-SUI surgery were above $5 \mathrm{k}+10=95$.

\section{Difficulty defecating after surgery}

Three documents included in the study reported the probability that patients will have difficulty defecating after pelvic restoration combined with anti-SUI surgery. It was found that 64 of the 936 patients in the experimental group had obstruction, while 48 of the 823 patients in the control 


\section{Identification of studies via databases and registers}

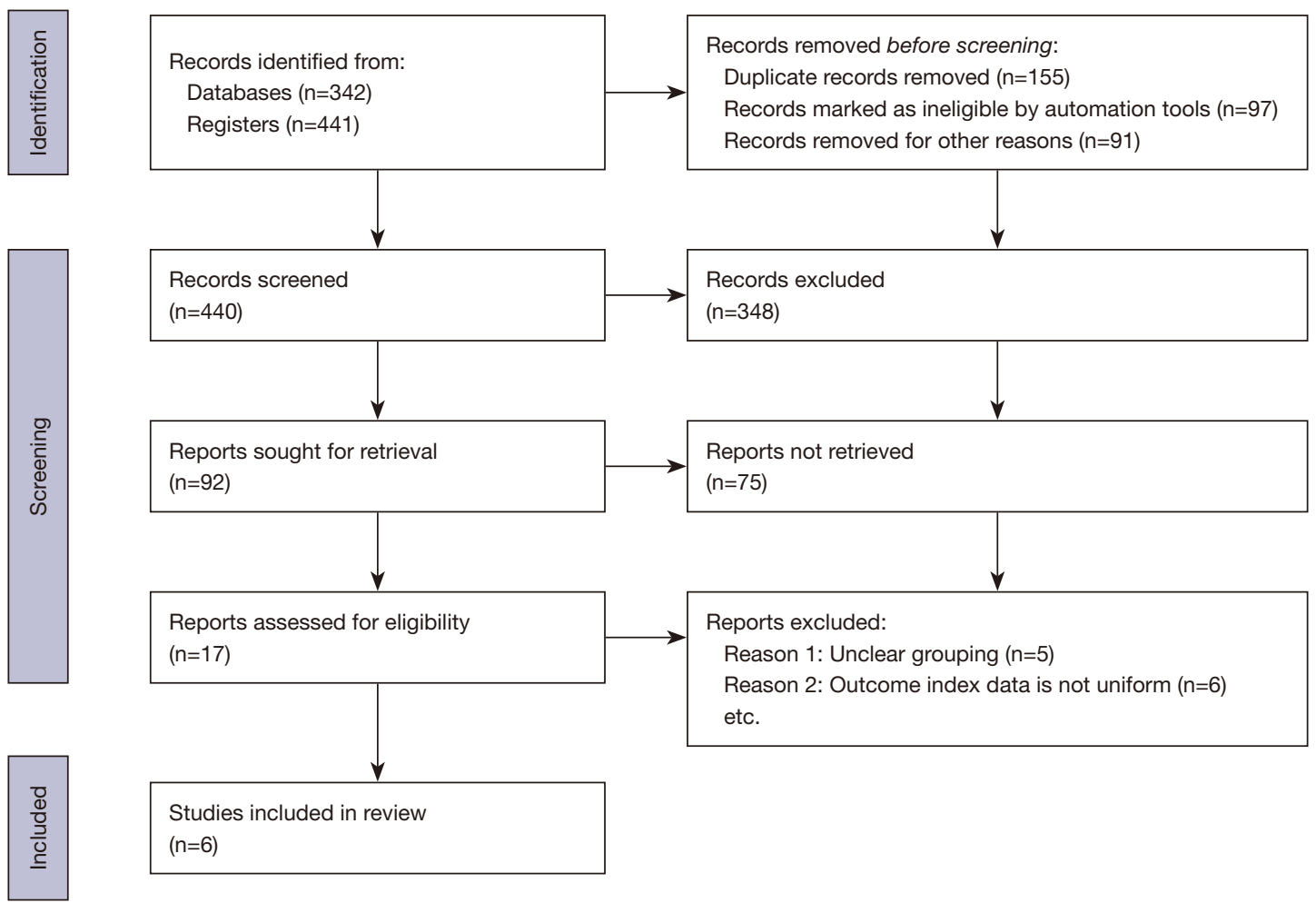

Figure 1 The literature retrieve process.

Table 1 The basic information of the articles included

\begin{tabular}{|c|c|c|c|c|c|c|c|}
\hline First author & $\begin{array}{c}\text { Year of } \\
\text { publication }\end{array}$ & $\begin{array}{l}\text { Experimental } \\
\text { group (case) }\end{array}$ & $\begin{array}{c}\text { Control } \\
\text { group (case) }\end{array}$ & Outcome indicators & $\begin{array}{l}\text { Random } \\
\text { method }\end{array}$ & $\begin{array}{c}\text { Patient's age } \\
\text { (years) }\end{array}$ & $\begin{array}{l}\text { Follow-up } \\
\text { time }\end{array}$ \\
\hline Tibi (11) & 2019 & 70 & 85 & $\begin{array}{l}\text { Postoperative obstruction rate, } \\
\text { postoperative bleeding rate, and } \\
\text { patient satisfaction score }\end{array}$ & $\begin{array}{c}\text { Randomized } \\
\text { control }\end{array}$ & 75.3 [70-80] & 12 months \\
\hline Krutova (12) & 2020 & 314 & 232 & $\begin{array}{l}\text { Quality of life impact index, incidence } \\
\text { of postoperative bleeding, incidence of } \\
\text { postoperative dyspareunia }\end{array}$ & $\begin{array}{c}\text { Randomized } \\
\text { control }\end{array}$ & $\begin{array}{l}61 \text { years old } \\
\text { on average }\end{array}$ & 12 months \\
\hline Cheng (13) & 2019 & 176 & 140 & $\begin{array}{l}\text { The incidence of postoperative } \\
\text { bleeding, hematoma, postoperative } \\
\text { obstruction, etc. }\end{array}$ & $\begin{array}{c}\text { Randomized } \\
\text { control }\end{array}$ & $\begin{array}{l}58 \text { years old } \\
\text { on average }\end{array}$ & 3 months \\
\hline Farid (14) & 2010 & 16 & 16 & $\begin{array}{l}\text { Incidence of postoperative obstruction, } \\
\text { patient satisfaction score, incidence of } \\
\text { postoperative bleeding }\end{array}$ & $\begin{array}{c}\text { Randomized } \\
\text { control }\end{array}$ & 56 [26-78] & 6 months \\
\hline Nieminen (16) & 2004 & 15 & 15 & $\begin{array}{l}\text { Patient satisfaction score, quality of life } \\
\text { impact score, incidence of bleeding }\end{array}$ & $\begin{array}{l}\text { Randomized } \\
\text { control }\end{array}$ & Ominous & 2 months \\
\hline
\end{tabular}


group had an obstruction. After the heterogeneity test, the results showed that $\mathrm{I}^{2}=0 \%, \mathrm{P}=0.67$, indicating there was obvious heterogeneity in the literature so the REM was used for analysis. The meta-analysis results showed that $\mathrm{OR}=1.22,95 \% \mathrm{CI}: 0.82-1.79, \mathrm{Z}=0.99$, and $\mathrm{P}=0.32$. Therefore, the two groups of patients had significant differences in the probability of having difficulty defecating

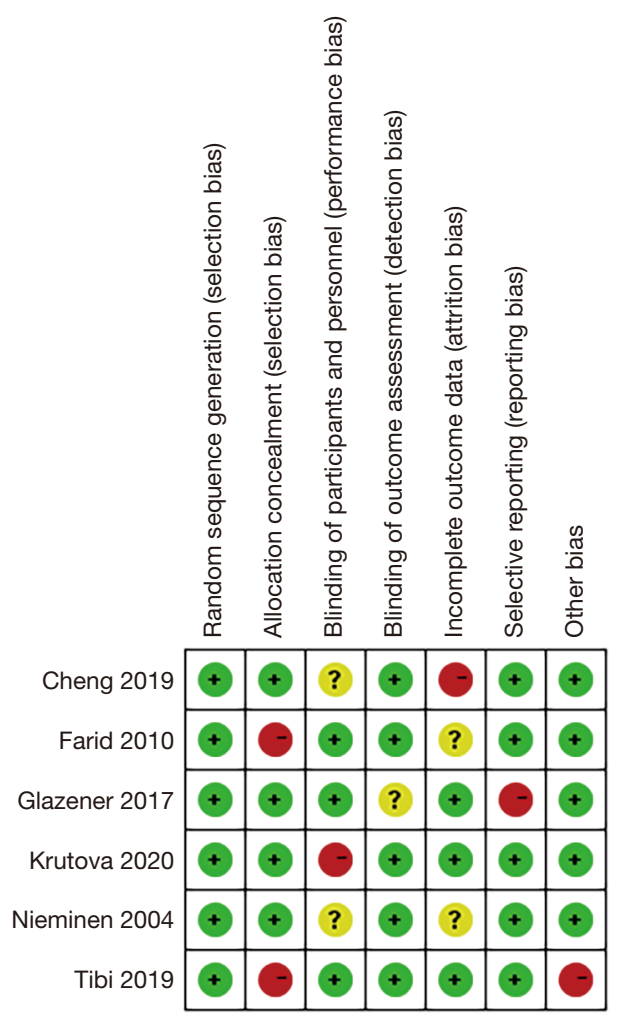

Figure 2 Bias risk assessment diagram of the included literature. after anti-SUI surgery $(\mathrm{P}<0.05)$, as shown in Figure 6.

As shown in Figure 7, the funnel chart was symmetrical, and most of the data corresponded to points within the $95 \%$ $\mathrm{CI}$, indicating that the publication bias was effective so that the results of the incidence of defecation difficulties after anti-SUI surgery were above $5 \mathrm{k}+10=95$.

\section{Postoperative dyspareunia}

Three documents included in the study reported the probability of dyspareunia after pelvic restoration combined with anti-SUI surgery. It was found that 37 of the 760 patients in the experimental group had dyspareunia, while 21 of the 683 patients in the control group had dyspareunia. After the heterogeneity test, the results showed that $\mathrm{I}^{2}=0 \%, \mathrm{P}=0.86$, indicating there was obvious heterogeneity in the literature so the REM was used for analysis. The meta-analysis results showed that $\mathrm{OR}=1.58,95 \% \mathrm{CI}: 0.91-2.74, \mathrm{Z}=1.63$, and $\mathrm{P}=0.10$. Therefore, the two groups of patients had significant differences in the probability of dyspareunia after anti-SUI surgery $(\mathrm{P}<0.05)$, as shown in Figure 8 .

As shown in Figure 9, the funnel chart was symmetrical, and most of the data corresponded to points within the $95 \%$ $\mathrm{CI}$, indicating that the publication bias was effective so that the results of the incidence of dyspareunia after anti-SUI surgery were above $5 \mathrm{k}+10=95$.

\section{Postoperative patient satisfaction score}

Three documents included in the study reported the patient satisfaction score after pelvic restoration combined with anti-SUI surgery. It was found that a total of 101 patients in the experimental group participated in the scoring, while

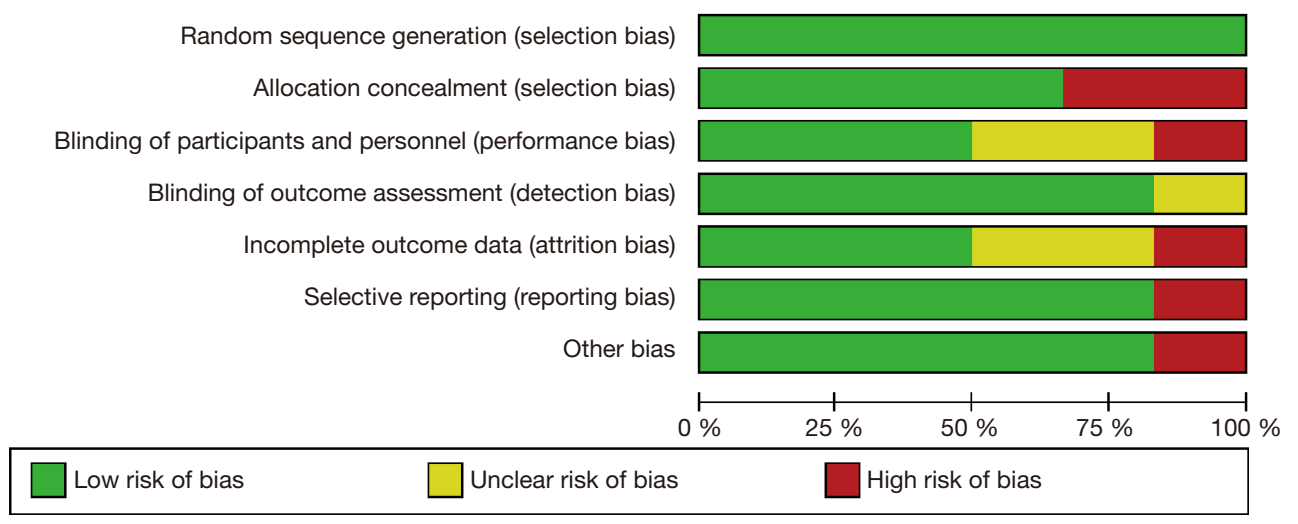

Figure 3 Bar chart of included literature bias risk assessment. 


\begin{tabular}{|c|c|c|c|c|c|c|c|c|c|c|c|}
\hline Study or Subqroup & \multicolumn{2}{|c|}{ Experimental } & \multicolumn{2}{|c|}{ Control } & \multicolumn{2}{|c|}{$\begin{array}{cc} & \text { Odds Ratio } \\
\text { Weight } & \text { M-H, Fixed, } 95 \% \mathrm{Cl} \\
\end{array}$} & \multicolumn{3}{|r|}{$\begin{array}{c}\text { Odds Ratio } \\
\text { M-H, Fixed, } 95 \% \mathrm{Cl}\end{array}$} & & \\
\hline Cheng 2019 & 11 & 176 & 8 & 140 & $15.5 \%$ & $1.10[0.43,2.81]$ & & & & & \\
\hline Farid 2010 & 2 & 16 & 1 & 16 & $1.6 \%$ & $2.14[0.17,26.33]$ & & & & & \\
\hline Glazener 2017 & 45 & 430 & 34 & 435 & $56.1 \%$ & $1.38[0.86,2.20]$ & & & & & \\
\hline Krutova 2020 & 16 & 314 & 7 & 232 & $14.2 \%$ & $1.73[0.70,4.27]$ & & & & & \\
\hline Nieminen 2004 & 2 & 15 & 4 & 15 & $6.4 \%$ & $0.42[0.06,2.77]$ & & & & & \\
\hline Tibi 2019 & 5 & 70 & 4 & 85 & $6.2 \%$ & $1.56[0.40,6.04]$ & & & & & \\
\hline Total $(95 \% \mathrm{Cl})$ & & 1021 & & 923 & $100.0 \%$ & $1.35[0.95,1.92]$ & & & & & \\
\hline Total events & 81 & & 58 & & & & & & & & \\
\hline $\begin{array}{l}\text { Heterogeneity: } \mathrm{Chi}^{2} \\
\text { Test for overall effec }\end{array}$ & $\begin{array}{l}2.11, d f= \\
Z=1.66\end{array}$ & $\begin{array}{l}(P=0 . \\
=0.10)\end{array}$ & $83) ; I^{2}=$ & & & & 0.01 & $\begin{array}{l}0.1 \\
{[\exp }\end{array}$ & ${ }_{\text {rimental] }}^{1}$ Favours & $\begin{array}{c}10 \\
\text { control }\end{array}$ & 100 \\
\hline
\end{tabular}

Figure 4 Forest plot of the incidence of obstruction after surgery in the two groups.

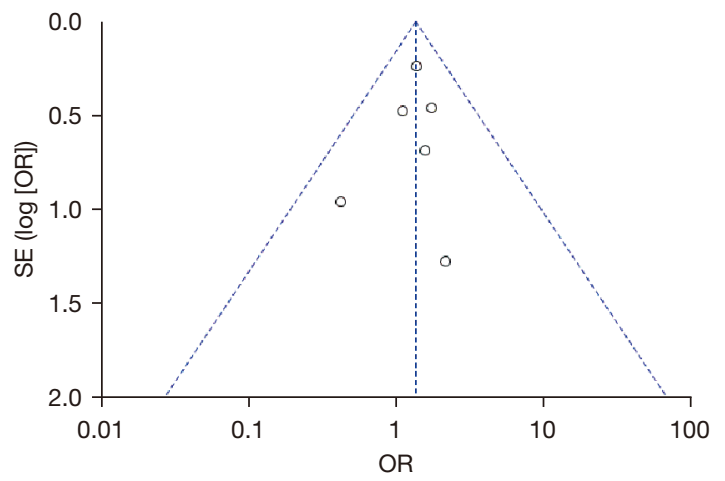

Figure 5 Funnel chart of the incidence of obstruction after surgery in the two groups.

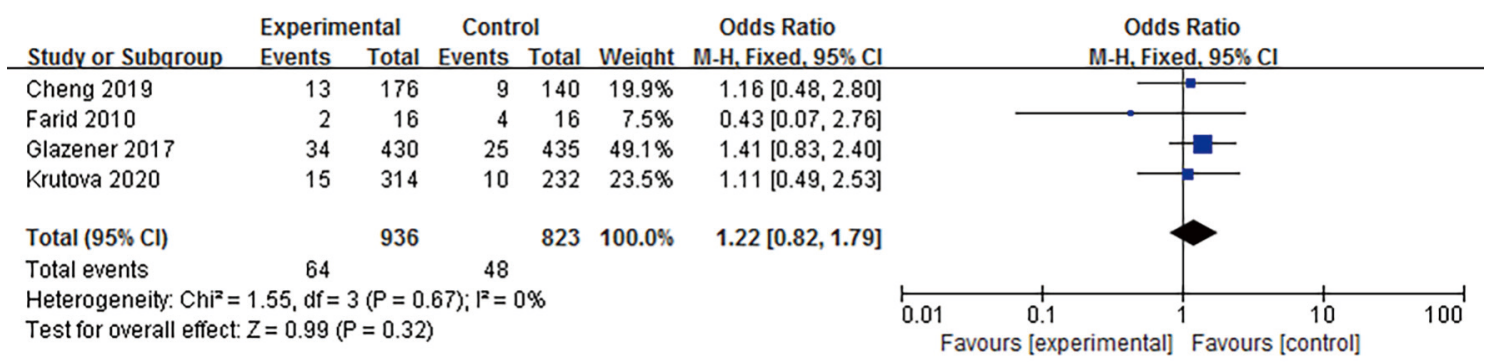

Figure 6 Forest plot of the incidence of difficulty defecating after surgery in the two groups.

116 patients in the control group participated in the scoring. After heterogeneity analysis, the results showed that $\mathrm{I}^{2}=0 \%$, $\mathrm{P}=0.58$, indicating that there was obvious heterogeneity in the literature and the FEM was used for analysis. The metaanalysis results showed that $\mathrm{OR}=0.77,95 \% \mathrm{CI}$ : $0.34-1.74$, $Z=0.63$, and $P=0.53$. Therefore, there was a significant difference in patient satisfaction scores between the two groups of patients after anti-SUI surgery $(\mathrm{P}<0.05)$, as shown in Figure 10.
As shown in Figure 11, the funnel chart was symmetrical, and most of the data corresponded to points within the $95 \%$ CI, indicating that the publication bias was effective so that the results of the patient satisfaction score after anti-SUI surgery were above $5 \mathrm{k}+10=95$.

\section{Discussion}

In this mate-analysis, 8 articles (11-18) were included. Of 


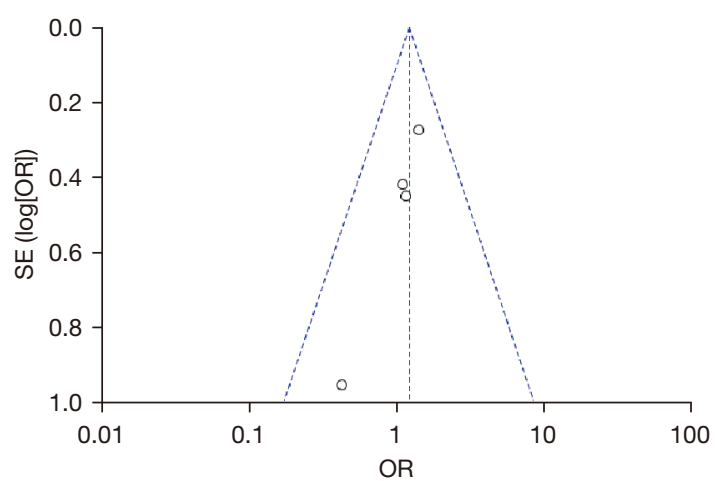

Figure 7 Funnel chart of the incidence of defecation difficulties after surgery in the two groups.

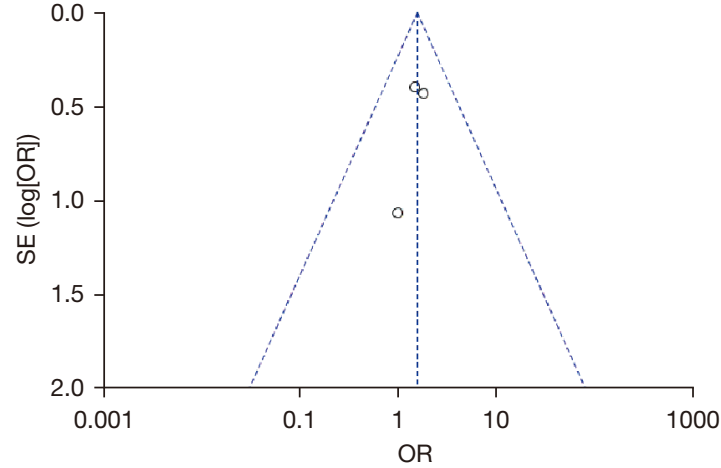

Figure 9 Funnel chart of the probability of dyspareunia after surgery in the two groups.

\begin{tabular}{|c|c|c|c|c|c|c|c|c|}
\hline Studv or Subgroup & $\begin{array}{l}\text { Experim } \\
\text { Events }\end{array}$ & $\begin{array}{l}\text { notal } \\
\text { Total }\end{array}$ & $\begin{array}{l}\text { Conts } \\
\text { Events }\end{array}$ & Total & Weight & $\begin{array}{c}\text { Odds Ratio } \\
\text { M-H, Fixed, } 95 \% \mathrm{Cl}\end{array}$ & $\begin{array}{c}\text { Odds Ratio } \\
\text { M-H, Fixed, } 95 \% \mathrm{Cl}\end{array}$ & \\
\hline Farid 2010 & 2 & 16 & 2 & 16 & $8.4 \%$ & $1.00[0.12,8.13]$ & & \\
\hline Glazener 2017 & 16 & 430 & 11 & 435 & $50.3 \%$ & $1.49[0.68,3.25]$ & & \\
\hline Krutova 2020 & 19 & 314 & 8 & 232 & $41.3 \%$ & $1.80[0.78,4.19]$ & & \\
\hline Total $(95 \% \mathrm{Cl})$ & & 760 & & 683 & $100.0 \%$ & $1.58[0.91,2.74]$ & & \\
\hline Total events & 37 & & 21 & & & & & \\
\hline \multicolumn{7}{|c|}{$\begin{array}{l}\text { Heterogeneity: chi }{ }^{2}=0.30, \mathrm{df}=2(\mathrm{P}=0.86) ; \mathrm{I}^{2}=0 \% \\
\text { Test for averall effect: } Z=1.63(\mathrm{P}=0.10)\end{array}$} & $\begin{array}{lll}0.001 & 0.1 & 1\end{array}$ & 1000 \\
\hline
\end{tabular}

Figure 8 Forest plot of the probability of dyspareunia after surgery in the two groups.

the 8 articles, a total of 6 studies reported information such as age, follow-up time, and observation indicators. Between the experimental group and the control group, there was no statistically significant difference $(\mathrm{P}>0.05)$. These 8 articles all adopted the method of random grouping to divide patients into experimental group and control group, but no blinding method was reported, and no loss during the follow-up was reported. The limitations of interventional measures in this study indicated that there may be measurement deviations between the experimental group and the control group. To improve the reliability and reference of the research, it is expected that the research method and design can be further improved in the future.

In recent years, pelvic restoration has attracted more and more attention with the aging of the population and the pursuit of quality of life. Transvaginal pelvic restoration has long since dominated mainstream surgical methods, including vaginal sacral fixation, sacral ligament fixation, and high uterosacral ligament suspension. Vaginal sacral fixation is usually done laparoscopically, and the latter two operations can be transvaginal or use laparoscopic examinations $(19,20)$. Non-surgical treatment is the first choice for the treatment of stress urinary incontinence, such as drug therapy and physical therapy, which can improve the frequency of urine leakage and improve the quality of life. However, due to the large individual differences, medication treatment is not the fastest and most effective method. Surgical treatment can be applied to patients with poor results of non-surgical treatment, and can treat pelvic floor organ prolapse. However, after surgical treatment, it is necessary to pay attention to the care of the postoperative site to prevent the occurrence of complications $(21,22)$. The analysis of the 8 studies showed suggested that pelvic restoration combined with anti-SUI surgery can improve the quality of life of patients and the satisfaction of patients after surgery, but because the surgery is harmful to the body, a series of complications will occur, such as postoperative obstruction, difficulty in defecation, postoperative bleeding, or hematoma. Pelvic floor reconstruction combined with anti-stress urinary incontinence surgery can correct the anatomical structure of the urethra and provide urinary control functions. However, it will increase the unnecessary economic burden of patients, and the two surgical treatments are not the same. The increase in surgical 


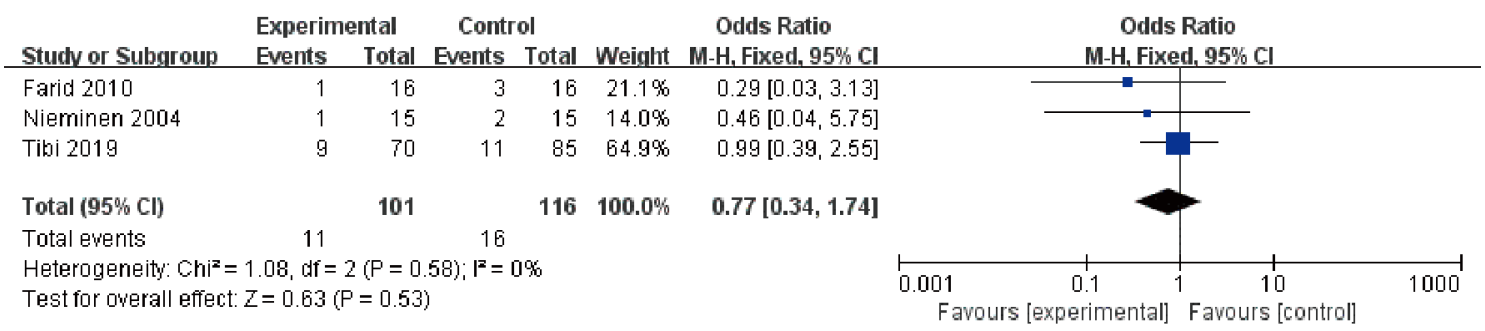

Figure 10 Forest plot of the postoperative satisfaction score of the two groups of patients.

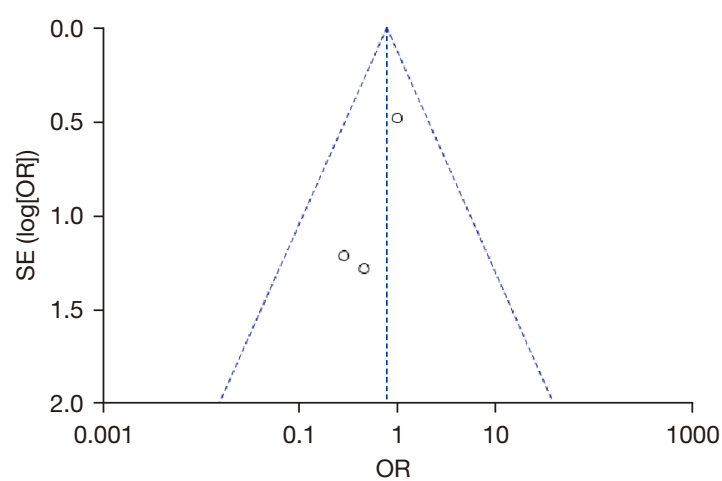

Figure 11 The funnel diagram of the satisfaction scores of the two groups of patients after surgery.

incisions may increase the incidence of postoperative complications. At present, there are few reports on the therapeutic effects of pelvic restoration combined with antiSUI surgery, mainly concentrating on subjective scores such as postoperative satisfaction scores and postoperative quality of life index. The information collected in this study may have publication bias, which affects the reliability of the mate-analysis. Above, pelvic restoration combined with anti-SUI surgery can bring great long-term benefits to patients and can improve the quality of life and satisfaction scores of the patients. However, the current research cannot obtain sufficient evidence and high-quality, large-sample, multi-center RCTs are needed to investigate the influence of pelvic restoration on the prognosis of the patients.

\section{Conclusions}

This study confirmed that pelvic restoration combined with anti-SUI surgery can improve the quality of life of patients after surgery, and the patient's satisfaction score was high. The analysis of the 8 studies showed suggested that pelvic restoration combined with anti-SUI surgery can improve the quality of life of patients and the satisfaction of patients after surgery, but because the surgery is harmful to the body, a series of complications will occur, such as postoperative obstruction, difficulty in defecation, postoperative bleeding, or hematoma. Since the follow-up time of each study was not consistent and the follow-up time of most studies was short, only approximately 2 months, it is impossible to make an accurate analysis of the long-term quality of life of patients. Above, pelvic restoration combined with antiSUI surgery can bring great long-term benefits to patients and can improve the quality of life and satisfaction scores of the patients. However, the current research cannot obtain sufficient evidence and high-quality, large-sample, multicenter RCTs are needed to investigate the influence of pelvic restoration on the prognosis of the patients.

\section{Acknowledgments}

Funding: None.

\section{Footnote}

Reporting Checklist: The authors have completed the PRISMA reporting checklist. Available at https://dx.doi. org/10.21037/apm-21-2737

Conflicts of Interest: All authors have completed the ICMJE uniform disclosure form (available at https://dx.doi. org/10.21037/apm-21-2737). The authors have no conflicts of interest to declare.

Ethical Statement: The authors are accountable for all aspects of the work in ensuring that questions related to the accuracy or integrity of any part of the work are appropriately investigated and resolved.

Open Access Statement: This is an Open Access article 
distributed in accordance with the Creative Commons Attribution-NonCommercial-NoDerivs 4.0 International License (CC BY-NC-ND 4.0), which permits the noncommercial replication and distribution of the article with the strict proviso that no changes or edits are made and the original work is properly cited (including links to both the formal publication through the relevant DOI and the license). See: https://creativecommons.org/ licenses/by-nc-nd/4.0/.

\section{References}

1. Abrams P, Cardozo L, Fall M, et al. The standardisation of terminology in lower urinary tract function: report from the standardisation sub-committee of the International Continence Society. Urology 2003;61:37-49.

2. Berghmans B. Physiotherapy for pelvic pain and female sexual dysfunction: an untapped resource. Int Urogynecol J 2018;29:631-8.

3. Hu JS, Pierre EF. Urinary Incontinence in Women: Evaluation and Management. Am Fam Physician 2019;100:339-48.

4. Yan W, Li X, Sun S, et al. Risk factors for female pelvic organ prolapse and urinary incontinence. Zhong Nan Da Xue Xue Bao Yi Xue Ban 2018;43:1345-50.

5. Wang K, Xu X, Jia G, et al. Risk Factors for Postpartum Stress Urinary Incontinence: a Systematic Review and Meta-analysis. Reprod Sci 2020;27:2129-45.

6. Milsom I, Gyhagen M. The prevalence of urinary incontinence. Climacteric 2019;22:217-22.

7. Qi X, Shan J, Peng L, et al. The effect of a comprehensive care and rehabilitation program on enhancing pelvic floor muscle functions and preventing postpartum stress urinary incontinence. Medicine (Baltimore) 2019;98:e16907.

8. Lee HY, Cho SY, Juan YS, et al. How to optimise urinary continence in anatomical endoscopic enucleation of the prostate? Andrologia 2020;52:e13621.

9. Slavin V, Gamble J, Creedy DK, et al. Perinatal incontinence: Psychometric evaluation of the International Consultation on Incontinence Questionnaire-Urinary Incontinence Short Form and Wexner Scale. Neurourol Urodyn 2019;38:2209-23.

10. Wagner H, Cheng JW, Austin Krishingner G, et al. Comparing the vaginal wall sling with autologous rectus fascia and polypropylene sling: Short term outcomes and patient satisfaction. Eur J Obstet Gynecol Reprod Biol 2018;231:98-103.
11. Tibi B, Vincens E, Durand M, et al. Comparison of different surgical techniques for pelvic floor repair in elderly women: a multi-institutional study. Arch Gynecol Obstet 2019;299:1007-13.

12. Krutova VA, Tarabanova OV, Khachetsukova AA, et al. Postoperative pelvic dysfunctions associated with the reconstruction of the pelvic floor. Minerva Ginecol 2020;72:202-11.

13. Cheng $\mathrm{W}, \mathrm{Bu} \mathrm{C}$, Hong $\mathrm{F}$, et al. Perioperative hemorrhagic complications in pelvic floor reconstructive surgery. Int Urogynecol J 2019;30:1141-6.

14. Farid M, Madbouly KM, Hussein A, et al. Randomized controlled trial between perineal and anal repairs of rectocele in obstructed defecation. World J Surg 2010;34:822-9.

15. Glazener CM, Breeman S, Elders A, et al. Mesh, graft, or standard repair for women having primary transvaginal anterior or posterior compartment prolapse surgery: two parallel-group, multicentre, randomised, controlled trials (PROSPECT). Lancet 2017;389:381-92.

16. Nieminen K, Hiltunen KM, Laitinen J, et al. Transanal or vaginal approach to rectocele repair: a prospective, randomized pilot study. Dis Colon Rectum 2004;47:1636-42.

17. Jelovsek JE, Barber MD, Brubaker L, et al. Effect of Uterosacral Ligament Suspension vs Sacrospinous Ligament Fixation With or Without Perioperative Behavioral Therapy for Pelvic Organ Vaginal Prolapse on Surgical Outcomes and Prolapse Symptoms at 5 Years in the OPTIMAL Randomized Clinical Trial. JAMA 2018;319:1554-65.

18. Solomon ER, St Marie P, Jones KA, et al. Anterior Bilateral Sacrospinous Ligament Fixation: A Safe Route for Apical Repair. Female Pelvic Med Reconstr Surg 2020;26:e33-6.

19. Lauterbach R, Gruenwald I, Matanes E, et al. The impact of vaginal hysterectomy and uterosacral ligament suspension on vaginal elasticity and sexual function. Eur J Obstet Gynecol Reprod Biol 2021;258:29-32.

20. Novara L, Sgro LG, Pecchio S, et al. Transvaginal high uterosacral ligament suspension: An alternative to McCall culdoplasty in the treatment of pelvic organ prolapse. Eur J Obstet Gynecol Reprod Biol 2019;240:278-81.

21. Fusco F, Abdel-Fattah M, Chapple CR, et al. Updated Systematic Review and Meta-analysis of the Comparative Data on Colposuspensions, Pubovaginal 
Slings, and Midurethral Tapes in the Surgical Treatment of Female Stress Urinary Incontinence. Eur Urol 2017;72:567-91.

22. Mühlstädt S, Hüsch T, Bauer RM. Differentiated surgical

Cite this article as: Liu J, Li L, Bv S, He P, Qiu M, Ma Z. Systematic review and meta-analysis of therapeutic effects of pelvic restoration combined with anti-stress urinary incontinence surgery on pelvic floor dysfunction. Ann Palliat Med 2021;10(11):11678-11687. doi: 10.21037/apm-21-2737 treatment of male stress urinary incontinence-between intention and reality? Urologe A 2019;58:640-50.

(English Language Editor: B. Draper) 